\title{
$\beta 1$-Integrins in the Developing Orbitofrontal Cortex Are Necessary for Expectancy Updating in Mice
}

\author{
(i)Lauren M. DePoy, ${ }^{1,2,3,4 \star}$ Lauren P. Shapiro ${ }^{1,2,3,5 \star}$ Henry W. Kietzman, ${ }^{1,2,3,4}$ Kaitlyn M. Roman, ${ }^{1,2,3,4}$ \\ and Shannon L. Gourley $y^{1,2,3,4,5}$ \\ ${ }^{1}$ Department of Pediatrics, ${ }^{2}$ Department of Psychiatry, ${ }^{3}$ Yerkes National Primate Research Center, ${ }^{4}$ Graduate Program in Neuroscience, and ${ }^{5} \mathrm{Graduate}$ \\ Program in Molecular and Systems Pharmacology, Emory University, Atlanta, Georgia 30329
}

\begin{abstract}
Navigating a changing environment requires associating stimuli and actions with their likely outcomes and modifying these associations when they change. These processes involve the orbitofrontal cortex (OFC). Although some molecular mediators have been identified, developmental factors are virtually unknown. We hypothesized that the cell adhesion factor $\beta 1$-integrin is essential to OFC function, anticipating developmental windows during which $\beta 1$-integrins might be more influential than others. We discovered that OFC-selective $\beta 1$-integrin silencing before adolescence, but not later, impaired the ability of mice to extinguish conditioned fear and select actions based on their likely outcomes. Early-life knock-down also reduced the densities of dendritic spines, the primary sites of excitatory plasticity in the brain, and weakened sensitivity to cortical inputs. Notwithstanding these defects in male mice, females were resilient to OFC (but not hippocampal) $\beta 1$-integrin loss. Existing literature suggests that resilience may be explained by estradiol-mediated transactivation of $\beta 1$-integrins and tropomyosin receptor kinase $\mathrm{B}(\operatorname{trk} \mathrm{B})$. Accordingly, we discovered that a trkB agonist administered during adolescence corrected reward-related decision making in $\beta 1$-integrin-deficient males. In sum, developmental $\beta 1$-integrins are indispensable for OFC function later in life.
\end{abstract}

Key words: CD29; cell adhesion; extracellular matrix; habit; juvenile; orbital

\section{Significance Statement}

The orbitofrontal cortex (OFC) is a subregion of the frontal cortex that allows organisms to link behaviors and stimuli with anticipated outcomes, and to make predictions about the consequences of one's behavior. Aspects of OFC development are particularly prolonged, extending well into adolescence, likely optimizing organisms' abilities to prospectively calculate the consequences of their actions and select behaviors appropriately; these decision making strategies improve as young individuals mature into adulthood. Molecular factors are not, however, well understood. Our experiments reveal that a cell adhesion protein termed " $\beta 1$-integrin" is necessary for $\mathrm{OFC}$ neuronal maturation and function. Importantly, $\beta 1$-integrins operate during a critical period equivalent to early adolescence in humans to optimize the ability of organisms to update expectancies later in life.

\section{Introduction}

Integrins are heterodimeric $(\alpha / \beta)$ cell adhesion proteins expressed throughout the nervous system. They form a link be-

\footnotetext{
Received Dec. 5, 2018; revised May 11, 2019; accepted June 3, 2019.

Author contributions: L.M.D., L.P.S., H.W.K., and S.L.G. designed research; L.M.D., L.P.S., H.W.K., K.M.R., and S.L.G. performed research; L.M.D., L.P.S., H.W.K., K.M.R., and S.L.G. analyzed data; L.M.D. wrote the first draft of the paper; L.M.D., L.P.S., H.W.K., and S.L.G. edited the paper.

We thank Aylet Allen, Michelle Sequeira, Courtni Andrews, Hayley Arrowood, and Weibo Fu for valuable contributions. This work was supported by NIH MH101477, MH117103, MH109208, DA034808, the ARCS Foundation, and the Emory Children's Center for Neuroscience Research. The Yerkes National Primate Research Center is supported by the Office of Research Infrastructure Programs/OD P510D011132. The Emory Viral Vector and Microscopy Cores are supported by an NINDS Core Facilities grant, P30NS055077. We also thank Dr. R. Jude Samulski of the UNC Viral Vector Core.

*L.M.P. and L.P.S. contributed equally to this work.

Correspondence should be addressed to Shannon L. Gourley at shannon.I.gourley@emory.edu.

https://doi.org/10.1523/JNEUROSCI.3072-18.2019

Copyright $\odot 2019$ the authors
}

tween extracellular matrix proteins and intracellular cytoskeletal signaling factors. Broadly speaking, $\alpha$ subunits determine extracellular binding partners, while $\beta$ subunits determine intracellular substrates. $\beta 1$-integrin protein and mRNA are present in the brain (Grooms et al., 1993; Pinkstaff et al., 1998), including postnatal frontal cortex (Shapiro et al., 2017a). $\beta 1$-integrins are also notably present in excitatory synapse postsynaptic densities (Schuster et al., 2001; Mortillo et al., 2012) and required for aspects of long-term potentiation (LTP) (Chan et al., 2006; Huang et al., 2006; Kramár et al., 2006; Babayan et al., 2012). Downstream signaling partners include cytoskeletal regulatory elements that support the formation and stabilization of dendrites and dendritic spines (Kerrisk and Koleske, 2013; Park and Goda, 2016).

$\beta 1$-integrins influence postnatal dendrite, dendritic spine, and synapse stability. For instance, forebrain-specific knock- 
down of Itgb1 (encoding $\beta 1$-integrin) results in dendrite retraction in hippocampal CA1 starting in late postnatal development in mice (Warren et al., 2012), a period equivalent to adolescence in humans (Spear, 2000). Working memory, a prefrontal cortical-dependent function, is also impaired (Chan et al., 2006). Additionally, genetic and local pharmacological inhibition of the $\beta 1$-integrin substrate Abl2/Arg kinase reduces accuracy in prefrontal cortical-dependent decision making tasks (Gourley et al., 2009, 2012a; DePoy et al., 2017). $\beta 1$-integrins thus appear necessary for prefrontal cortical function, but supporting evidence remains indirect, given that prior reports used either conditional knock-out mice lacking site specificity or local infusions of drugs that act on $\beta 1$-integrin signaling partners rather than $\beta 1$-integrin itself.

Within the frontal cortex, the orbitofrontal cortex (OFC) is conceptualized as building "task spaces," allowing organisms to link behaviors and stimuli with anticipated outcomes, and to make predictions about the future (Wilson et al., 2014; Stalnaker et al., 2015). Another function commonly ascribed to the OFC is updating expectations when familiar contingencies change (Sul et al., 2010; Fiuzat et al., 2017). Across rodent and primate species, aspects of OFC development are particularly prolonged, extending well into adolescence (reviewed Shapiro et al., 2017a). For example, in rats, OFC volume peaks at $\sim$ postnatal day 30 (P30), whereas medial prefrontal cortical volume peaks earlier, at P24 (Van Eden and Uylings, 1985). OFC development during adolescence likely optimizes organisms' ability to prospectively calculate the consequences of their actions and select behaviors appropriately; these decision making strategies improve as young individuals mature into adulthood.

Given that $\beta 1$-integrins are involved in postnatal neuron maturation, we tested whether they were involved in OFC function, as well. Specifically, we aimed to identify developmental windows, if any, during which $\beta 1$-integrins might be indispensable for OFC function later in life. We were motivated by evidence that embryonic-onset Itgb1 knock-down causes synapse loss in the hippocampus later in life (Warren et al., 2012), while postnatal-onset knock-down does not (Chan et al., 2006). Further, embryonic-onset knock-down disrupts cortical layering and impairs synaptic responses to high-frequency stimulation and LTP in the hippocampus; of these, postnatal-onset knockdown affects only LTP (Huang et al., 2006). These patterns together reveal developmental critical periods during which $\beta 1$-integrin tone has enduring anatomical and functional consequences in the hippocampus. Identifying when and where individual adhesion proteins are indispensable for complex behavior is important, given that they are vulnerable to disruption by stressors and drugs of abuse (see Discussion), which could conceivably account for long-term behavioral effects of drugs or stress during specific developmental periods. Our findings reveal a critical period during early adolescence when $\beta 1$-integrins in the OFC support expectancy updating later in life.

\section{Materials and Methods}

\section{Subjects}

Male and female transgenic Itbg $1^{\text {tm1Efu }}$ mice were bred on a mixed strain background (C57BL/6J;129X1/SvJ) (Raghavan et al., 2000; The Jackson Laboratory). loxP sites flank exon 3 of Itgb1, and Cre-recombinase (Cre) deletes this exon. For dendritic spine imaging, these mice were crossed with mice expressing yellow fluorescence protein (YFP) under the Thy 1 gene ( $\mathrm{H}$ line; Feng et al., 2000; The Jackson Laboratory). All mice were maintained on a $12 \mathrm{~h}$ light cycle (0800 on), experimentally naive, and provided food and water ad libitum unless otherwise indicated. Proce- dures were approved by the Emory University institutional animal care and use committee.

\section{Viral vector infusion}

Infusions occurred at P24, P31, or P56, as indicated in the figure timelines. These ages correspond to preadolescence, adolescence, and young adulthood, respectively (Spear, 2000). Viruses were as follows: (1) lentiviruses expressing Cre or GFP under the cytomegalovirus (CMV) promoter; (2) adeno-associated viruses (AAV8) expressing Cre+mCherry or mCherry alone under the CaMKIIa promoter; or (3) AAV8-CaMKIIahM4Di-GFP (Gi-coupled Designer Receptors Exclusively Activated by Designer Drugs, or "DREADDs;" see Urban and Roth, 2015 for review) or AAV8-CaMKIIa-GFP. Lentiviral vectors were sourced from the Emory Viral Vector Core, and AAVs were sourced from the UNC Viral Vector Core and ADDGene.

Mice were anesthetized with ketamine/dexdomitor. Mice were placed in a digitized stereotaxic frame (Stoelting), the head shaved, scalp incised, skin retracted, and head leveled. Burr holes were drilled. For OFC infusions, viral vectors were infused over $5 \mathrm{~min}$ in a volume of $0.5 \mu \mathrm{l}$ at $\mathrm{AP}+2.6, \mathrm{DV}-2.8, \mathrm{ML} \pm 1.2$. For prelimbic cortex (PL) infusions, AAV8hM4Di-GFP or AAV8-GFP was delivered over $5 \mathrm{~min}$ in a volume of 0.5 $\mu l$ at $\mathrm{AP}+2.0, \mathrm{DV}-2.8, \mathrm{ML} \pm 0.1$. For hippocampal infusions, lenti-Cre or lenti-GFP was delivered in a volume of $1 \mu \mathrm{l} /$ site over $10 \mathrm{~min}$ at $\mathrm{AP}-1.3$, $\mathrm{DV}-2.0, \mathrm{ML} \pm 1.0$, and AP $-2.1, \mathrm{DV}-2.2$, and $\mathrm{ML} \pm 1.5 \mathrm{~mm}$. Throughout, needles were left in place for $\geq 5$ additional minutes after infusion before withdrawal and suturing. After surgery, mice were left undisturbed for $\sim 32 \mathrm{~d}$ and then proceeded to behavioral testing or euthanasia.

\section{Western blot analyses}

Mice bearing viral vectors were rapidly decapitated and brains were frozen at $-80^{\circ} \mathrm{C}$ and then sectioned into $1 \mathrm{~mm}$ sections. The OFC was dissected by a single experimenter using a $1 \mathrm{~mm}$ tissue core, which would be expected to collect both virus-infected and uninfected cells. Tissue was homogenized by sonication in lysis buffer [100 $\mu \mathrm{l}: 137 \mathrm{~mm} \mathrm{NaCl}, 20 \mathrm{~mm}$ Tris-HCl, pH 8, 1\% Igepal, 10\% glycerol, 1:100 Phosphatase Inhibitor Cocktails 2 and 3 (Sigma-Aldrich), 1:1000 Protease Inhibitory Cocktail (Sigma-Aldrich)]. Protein concentrations were determined by Bradford colorimetric assay (Pierce) and $50 \mu \mathrm{g} / \mathrm{sample}$ was separated by SDSPAGE on a $12 \%$ gradient Tris-glycine gel (Bio-Rad). After transfer to PVDF membrane, membranes were blocked with $5 \%$ nonfat milk.

Primary antibodies were anti-CD29 ( $\beta 1$-integrin; BD Transduction Laboratories; Mouse; 1:50) and anti-HSP-70 (Santa Cruz Biotechnology; Mouse; 1:5000), serving as a loading control. Immunoreactivity was assessed using a chemiluminescence substrate (Pierce) and measured using a ChemiDoc MP Imaging System (Bio-Rad).

\section{Behavioral testing}

Food-reinforced response training. Mice were food restricted to $~ 90 \%$ of their free-feeding body weight. Mice were trained to nose poke for food reinforcers (20 mg, grain-based Bio-Serv Precision Pellets) in Med Associates operant conditioning chambers equipped with 2 nose poke recesses and a separate food magazine. Responding was reinforced using a fixed ratio 1 (FR1) schedule such that 30 pellets were available for responding on each of two distinct nose poke recesses. Sessions ended at 70 min or 60 pellets acquired. Mice were trained for at least 7 sessions or until they acquired all 60 pellets within $70 \mathrm{~min}$. Response acquisition curves represent both responses/min for the last seven training sessions.

Action-outcome contingency degradation. A modified version of classical action-outcome contingency degradation was used, as in our prior reports (Gourley et al., 2012b, 2013a; Swanson et al., 2015), and similar to that of Barker et al. (2013): In a 25 min "nondegraded" session, one nose poke aperture was occluded, and responding on the other aperture was reinforced using an FR1 schedule of reinforcement, as during training. In the 25 min "degraded" session, the opposite aperture was occluded, and pellets were delivered into the magazine at a rate matched to each animal's reinforcement rate from the previous session. Under these conditions, only $\sim 7 \%$ of pellets are delivered (by chance) within $2 \mathrm{~s}$ after a response (Butkovich et al., 2015). Thus, this response becomes significantly less predictive of reinforcement than the other. These sessions, and 
which action-outcome contingency was degraded, were counterbalanced with the following exception: Two mice did not stably acquire the responses due to side preferences. Both were control mice in the final experiment, and we degraded the action-outcome contingency associated with the preferred nose poke response, biasing against our hypothesis that these mice would later select actions based on anticipated consequences.

The following day, both apertures were available during a $10 \mathrm{~min}$ probe test conducted in extinction. Sensitivity to action-outcome relationships is reflected by preferential engagement of the response that is likely to be reinforced. Meanwhile, engaging both familiar responses equivalently is interpreted as a failure in associating actions with their outcomes.

Within 1 week after the probe test, mice were tested in one of the following assays: signaled reinforcement, response reversal and extinction, auditory fear conditioning and extinction, or contextual fear conditioning. In the case of fear conditioning experiments, mice were returned to ad libitum feeding before testing. These tasks are described next.

Signaled reinforcement. Interjecting stimuli, such as tones and lights, during the brief delay between a behavior and reinforcer delivery can facilitate response acquisition, serving as instructive cues (Spence, 1947). Mice that had been previously tested in the action-outcome contingency degradation task were trained to nose poke for food reinforcers in contextually distinct Med Associates conditioning chambers equipped with three nose poke recesses. Responding on the "active" nose poke aperture resulted in a $2 \mathrm{~s}, 2.9 \mathrm{kHz}$ tone, extinction of the house light, presentation of a stimulus light above the magazine, and finally, a food pellet. Responding was reinforced according to an FR1 schedule. Nonreinforced responses on the remaining two apertures generated neither tones nor lights. Daily sessions ended at $15 \mathrm{~min}$.

Response reversal and extinction. A previously recessed lever was extended, and mice were reinforced for lever pressing according to an FR1 schedule for $25 \mathrm{~min}$. Meanwhile, nose poking had no consequences (response reversal). After four sessions, reinforcement was then withheld entirely for 5 more sessions (extinction).

Auditory fear conditioning and extinction. Fear conditioning chambers (Coulbourn) equipped with USB cameras and computer-operated FreezeFrame Software (Actimetrics) were used. Mice were acclimated to the testing room for $1 \mathrm{~h}$ and then habituated to the conditioning chambers for $15 \mathrm{~min}$, for 2 consecutive days. Next, mice were placed in the chambers, and after $3 \mathrm{~min}$, they received the first of 5 tone + shock pairings. Each trial consisted of a $30 \mathrm{~s}$ tone $(6 \mathrm{kHz}, 75 \mathrm{~dB})$ coterminating with a $1 \mathrm{~s}, 0.6 \mathrm{~mA}$ foot shock. The following $2 \mathrm{~d}$, mice were placed in contextually distinct chambers, habituated for $3 \mathrm{~min}$, and then presented with $1530 \mathrm{~s}$ tones over $15 \mathrm{~min}$ in the absence of shock. The percentage of time freezing during these $30 \mathrm{~s}$ trials, and in the $30 \mathrm{~s}$ before the first tone, was compared between groups. The absence of any movement excluding respiration was considered freezing and calculated by FreezeFrame.

Contextual fear conditioning. Separate mice were fear conditioned as above, except no tone was present. The following day, mice were returned to the same context, and freezing during $15 \mathrm{~min}$ was recorded. Because contextual fear conditioning can be affected by sex hormones (Koss and Frick, 2017), freezing is reported as a function of both virus group and estrous phase (assessed per Byers et al., 2012).

Locomotor activity was monitored in fear-conditioned mice using customized Med Associates chambers equipped with 16 photobeams. Mice were placed in the chambers for $1 \mathrm{~h}$, and beam breaks were compared between groups.

\section{Clozapine $\mathrm{N}$-oxide (CNO) administration and sucrose consumption}

Mice were first individually housed with familiar bedding in a quiet room. Water was then withheld for $19 \mathrm{~h}$. Next, mice were administered CNO (Sigma-Aldrich; $1 \mathrm{mg} / \mathrm{kg}$, in 2\% DMSO and saline, i.p.). All mice received $\mathrm{CNO}$ regardless of viral vector condition to equally expose animals to any unintended consequences of CNO (Gomez et al., 2017). One hour later, mice had access to water (day 1, baseline) or a $1 \%$ w/v sucrose solution (days 2-4) for $4 \mathrm{~h}$. Then, liquid was removed until the following day. Liquid consumption is reported as percentage body weight.

\section{7,8-dihydroxyflavone (7,8-DHF) administration}

From P31 to P38, mice received daily intraperitoneal injections of the trkB agonist 7,8-DHF (Sigma-Aldrich; $3 \mathrm{mg} / \mathrm{kg}$ from Barfield et al., 2017, dissolved in $17 \%$ DMSO and saline) or vehicle. Another control group was left undisturbed. Groups were randomized.

\section{Histology}

Mice used for behavioral testing were killed by rapid decapitation. Brains were submerged in $4 \%$ paraformaldehyde for $48 \mathrm{~h}$, then transferred to $30 \% \mathrm{w} / \mathrm{v}$ sucrose, followed by sectioning into $50 \mu \mathrm{m}$-thick sections on a microtome held at $-15^{\circ} \mathrm{C}$. Viral vector infusion sites were verified by immunostaining for Cre as described previously (DePoy et al., 2013). Alternatively, GFP or mCherry was imaged.

\section{Dendritic spine imaging}

YFP-expressing Itgb1 "floxed" mice were infused into one hemisphere with AAV8-mCherry and in the opposite hemisphere, AAV8-mCherryCre. Upon euthanasia by rapid decapitation, brains were submerged in chilled $4 \%$ paraformaldehyde for $48 \mathrm{~h}$, then transferred to $30 \% \mathrm{w} / \mathrm{v} \mathrm{su}-$ crose, followed by sectioning into $50-\mu \mathrm{m}$-thick sections on a microtome held at $-15^{\circ} \mathrm{C}$. Unobstructed dendritic segments of neurons coexpressing mCherry and YFP were imaged on a spinning disk confocal system (VisiTech International) on a Leica microscope. Z-stacks were collected with a $100 \times 1.4$ numerical apertive objective using a $0.1 \mu \mathrm{m}$ step size, sampling above and below the dendrite. After imaging, we confirmed at $10 \times$ that the image was collected from the ventrolateral OFC.

Independent segments from secondary branches within $25-150 \mu \mathrm{m}$ of the soma were collected ( $n=2-9 /$ mouse). Each protrusion $\leq 4.5 \mu \mathrm{m}$ was considered a spine. Bifurcated spines were considered singular units. Dendritic spines were first counted manually by a single blinded rater, and spine number for each segment was divided by the length of the segment to generate spine densities. Dendritic spines were then reconstructed in 3D and classified by a separate blinded rater using Imaris software (as per Gourley et al., 2013b). Dendritic spines with a head diameter $>2$ times neck diameter and a length $>0.6 \mu \mathrm{m}$ were classified as "mushroom-type" spines. "Non-mushroom-type" spines were shorter than $0.6 \mu \mathrm{m}$ and/or had a head width that was $<2$ times neck diameter (parameters from Cooper and Koleske, 2014). Throughout, each hemisphere contributed a single density value (its average) to statistical analyses, except for cumulative density comparisons of spine lengths, in which case each spine was considered an independent sample.

\section{Statistical analyses}

For Western blotting, densitometry values were normalized to the corresponding loading control, then to the control sample mean from the same membrane to control for variance between gels. Values were compared by unpaired $t$ test. For behavioral experiments, response rates, freezing scores, and fluid consumption were compared by ANOVA with repeated measures when appropriate and Tukey's post hoc comparisons after interactions. Any positive results of post hoc comparisons (i.e., $p \leq$ $0.05)$ are indicated graphically. Locomotor counts and context-elicited freezing scores were compared by unpaired $t$ tests. For dendritic spine experiments, unpaired $t$ tests or ANOVAs were applied to density comparisons, with each hemisphere considered an independent sample. Dendritic spine lengths were compared by Kolmogorov-Smirnov comparisons, with each dendritic spine representing an independent sample. $p \leq 0.05$ was considered significant throughout. Values $>2$ SDs above the mean were considered outliers and were excluded.

\section{Results}

$\beta 1$-integrins are involved in neuronal development and plasticity. We hypothesized that they are indispensable for OFC function as well. To reduce $\beta 1$-integrins, we delivered viral vectors expressing mCherry-Cre into the ventrolateral OFC of floxed Itgbl mice. Throughout, timelines indicate the age of viral vector infusion and subsequent testing. Histological analyses revealed 


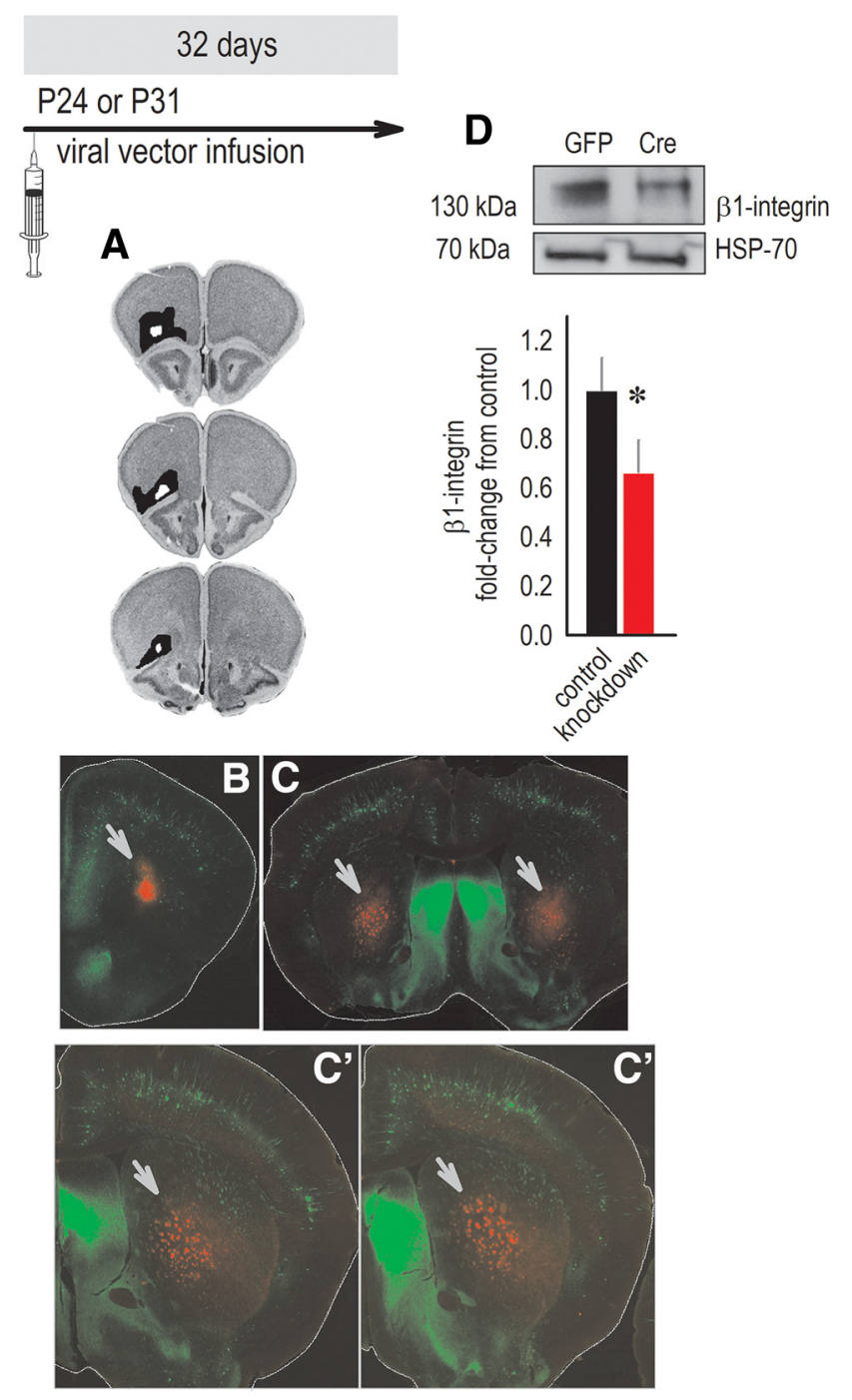

Figure 1. Viral-mediated Itgb1 silencing reduces $\beta 1$-integrin protein levels. Experimental timeline is shown at the top. $\boldsymbol{A}$, Representations of OFC viral vector infusion sites in the behavioral experiments throughout this report, with black indicating the largest observed infection and white the smallest, transposed onto images from the Mouse Brain Library (Rosen et al., 2000). $\boldsymbol{B}$, Representative mCherry in the ventrolateral OFC (arrow) imaged in YFP-expressing mice for contrast. $\boldsymbol{C}$, mCherry-expressing fibers (arrows) were detected in characteristic patterns in the downstream dorsal striatum (cf. Schilman et al., 2008). D, $\beta 1$-integrin levels were lower in gross tissue punches collected from the OFC of knock-down mice. Incomplete protein loss was expected, given that tissue punches contained both infected and uninfected cells. Densitometry values were normalized to the corresponding loading control (HSP-70), and representative blots are adjacent, $n=5$ control, $n=6$ knock-down. Data are shown as mean + SEM. ${ }^{*} p=0.05$. Each blot was run at least twice.

that viral vectors infected primarily the ventrolateral OFC as intended, with some spread into the dorsolateral OFC and agranular insula (Fig. 1A,B). Mice with infections spreading dorsally into M2 and/or ventrally beyond the boundaries of the OFC were excluded (one to four mice/cohort). Group sizes are reported in the figure captions and do not count excluded mice. Labeled axons were visualized in the dorsal striatum, revealing characteristic topographically organized innervation of the medial and ventral subregions (Fig. 1C; cf., Schilman et al., 2008). Viralmediated gene knock-down reduced $\beta 1$-integrin levels by $34 \%$ in gross OFC tissue punches $\left(t_{(9)}=1.8, p=0.05\right.$; Fig. $\left.1 D\right)$. Incomplete protein loss was expected, given that tissue punches contained both infected and uninfected cells.

\section{$\beta 1$-integrins in the developing OFC are necessary for expectancy updating}

We first assessed whether early-life (viral vector infusion at P24) Itgb1 knock-down affected the ability of mice to extinguish conditioned fear, as the OFC is involved in several forms of aversionbased conditioning (Shiba et al., 2016). Further, conditioned fear extinction requires mice to update expectancies when outcomes change, a function of the OFC (Stalnaker et al., 2015). When a mild foot shock was paired with a tone, tone-elicited freezing increased, with no differences between groups ( $F>1$; Fig. $2 A)$. When mice were exposed to the tone in a novel context in the absence of the foot shock, however, Itgb1-deficient mice retained high freezing levels (extinction day 1, interaction $F_{(15,240)}=2.1$, $p=0.01$; Fig. $2 A$ ). The same extinction impairment was detected the following day (extinction day 2, interaction $F_{(15,240)}=2.4$, $p=0.004$; Fig. $2 A$ ). We identified no differences in locomotor activity that could potentially account for differential freezing $(p>0.7$; Fig. $2 B)$, thus $\beta 1$-integrins in the OFC appear necessary for conditioned fear extinction.

Next, we tested the ability of mice to update reward-related expectancies. Again, we infused CaMKII-driven AAVs at P24 to reduce Itgb1. Although the lateral-most regions of the OFC are argued to specialize in stimulus-outcome representations (Rudebeck et al., 2008), experiments using lesion and inactivation strategies suggest that the ventrolateral subregion infected here is also involved in modifying and solidifying action-outcome expectations across rodent and primate species (for discussion, see Whyte et al., 2019). Thus, we tested mice in an instrumental contingency degradation procedure. Mice were first trained to perform food-reinforced nose poke responses. We detected a session $\times$ group interaction $\left(F_{(6,108)}=3.59, p=\right.$ $0.003]$, hinting at $\beta 1$-integrin influences over instrumental response training, but no post hoc comparisons reached significance (Fig. 2C). Next, we reduced the likelihood that one familiar response would be reinforced, "degrading" one action-outcome association. Control mice updated their response strategies, preferentially generating the action most likely to be reinforced during a probe test, whereas knock-down mice failed to modify their behaviors, responding on both apertures at equivalent rates (interaction $F_{(1,16)}=4.8, p=0.04$; Fig. $\left.2 D\right)$. Thus, $\beta 1$-integrins in the OFC appear necessary for updating reward-related response strategies.

We focused the rest of our investigation on reward-related responding. Our experiments above using CaMKII-driven viral vectors suggested that behavioral abnormalities can be attributable to loss of $\beta 1$-integrins specifically in excitatory neurons. As a replication, we infused a new cohort of floxed Itgb1 mice at P24 with lentiviruses, which favor neurons (with moderate glial infection anticipated; see Ehrengruber et al., 2001). We hypothesized that, despite using a different viral vector, Itgb1 deficiency would again occlude response updating and, further, that effects might be age dependent. As with AAV-mediated knock-down, lentiviral-mediated Itgbl knock-down modestly affected instrumental response training (interaction $F_{(6,108)}=2.3, p=0.04$ ], with post hoc comparisons indicating that Itgbl knock-down transiently delayed the ability of mice to acquire all available reinforcers (lower response rates on session 6; Fig. 2E). Further, as with AAV-mediated gene knock-down, lentiviral-mediated knock-down mice failed to modify their response preferences when one familiar action-outcome association was degraded (interaction $F_{(1,18)}=15.9, p<0.001$; Fig. $2 F$ ).

We next reinstated responding across several short, reinforced sessions. In this case, we provided auditory and visual stimuli during the brief delay between a reinforced response 

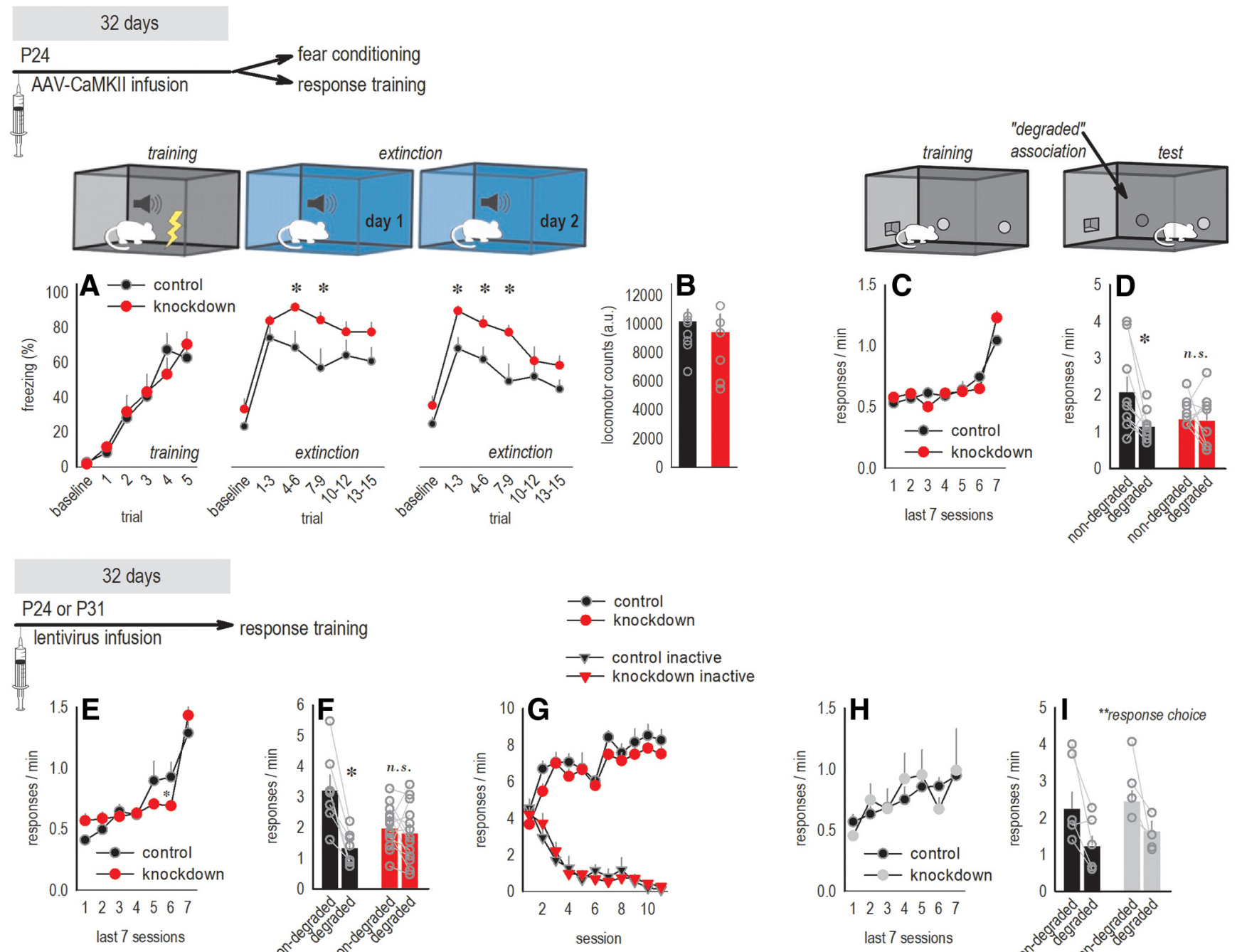

response training

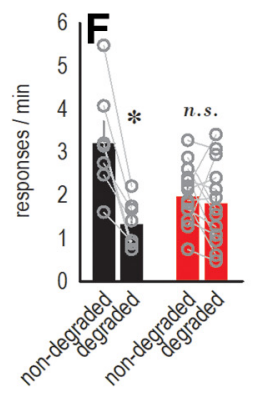

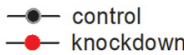

$\rightarrow-$ control inactive $\rightarrow-$ knockdown inactive

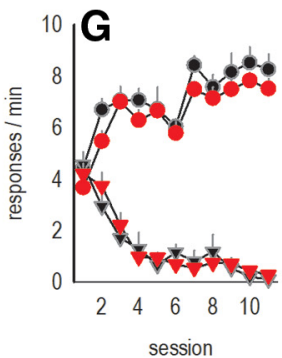

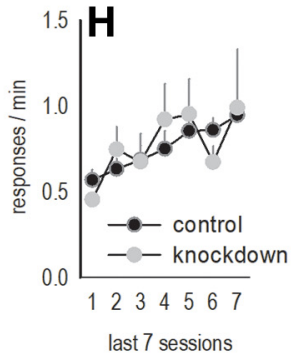

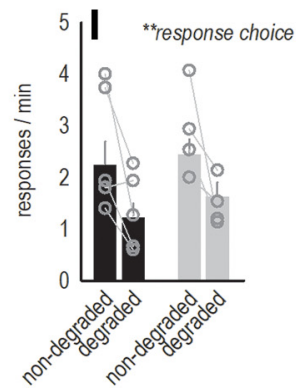

Figure 2. $\quad \beta 1$-integrins in the developing OFC are necessary for expectancy updating. Experimental timelines are shown at the top of each row. $\boldsymbol{A}$, In a fear conditioning procedure, freezing increased with repeated tone-shock pairings. When exposed to conditioned stimuli in the absence of foot shock (extinction), Itgb1 knock-down mice froze more, a failure in fear extinction. Exaggerated freezing was again detected the following day, indicated by a break in the $x$-axis ( $n=8$ control, 9 knock-down). $\boldsymbol{B}$, Locomotor activity did not differ between groups. $\boldsymbol{C}$, Separate mice were trained to respond equivalently on two nose poke apertures for food reinforcers. Response rates represent both responses/min. $\boldsymbol{D}$, After training, the likelihood of reinforcement associated with one nose poke response was reduced (degraded). Itgb1 knock-down mice failed to differentiate between responses, failing to update outcome expectancies ( $n=9$ control, $n=9 \mathrm{knock}$-down). $\boldsymbol{E}$, We focused the rest of our report on reward-related responding, first replicating our experiments using lentiviral-mediated gene silencing. Mice were trained to respond on two nose poke apertures for food reinforcers. $\boldsymbol{F}$, When the likelihood of reinforcement associated with one nose poke response was reduced (degraded), again, Itgb1 knock-down mice failed to differentiate between familiar responses ( $n=7$ control, 13 knock-down). G, Groups did not differ, however, when auditory and visual stimuli signaled reinforcer delivery. In this condition, both groups readily differentiated between reinforced and nonreinforced ("inactive") behaviors. $\boldsymbol{H}, \boldsymbol{I}$, When viral vectors were delayed until P31, no effects on response training $(\boldsymbol{H})$ or action- outcome conditioning $(\boldsymbol{I})$ were detected ( $n=5$ control, $n=4$ knock-down). Data are shown as means + SEM, except gray symbols represent individual mice. ${ }^{*} p<0.05,{ }^{* *} p=0.005$ main effect of response choice, with no interactions. n.s., Nonsignificant. Experiments were conducted at least twice. Illustration credit: A. Allen.

and pellet delivery. These cues signaled reinforcer availability, reducing the need for mice to generate expectancies regarding the consequences of their actions. Under these conditions, both groups preferentially engaged the reinforced behavior without any effect of knock-down (no interaction $F<1$; no main effect of knock-down $F_{(1,18)}=1.1, p=0.3$; Fig. $\left.2 G\right)$. Thus, $\beta 1$-integrins in the OFC appear necessary for updating reward-related response strategies, particularly when circumstances are ambiguous.

Next, a separate group of mice was infused with lentiviral vectors later, at P31, and tested identically. In this case, we identified no differences in instrumental response training $(F<1$; Fig. $2 H$ ). Further, all mice preferentially engaged the action that was more likely to be reinforced when the other ceased to be rewarded, evidence of intact action-outcome expectancies (main effect of response $F_{(1,9)}=13.6, p=0.005$; no interactions $F<1$; Fig. $2 I)$. Thus, disrupting $\beta 1$-integrins in late postnatal development has no obvious effect on response selection.

\section{$\boldsymbol{\beta} 1$-integrins in the OFC are necessary for dendritic spine stability and sensitivity to cortical inputs}

We next determined the effect of reducing $\beta 1$-integrins on dendritic spines, the primary sites of excitatory plasticity in the brain. We hypothesized that, as in our behavioral studies, knock-down initiated early in life (at P24) would have effects, whereas knockdown initiated later (at P31) would not. We crossed Itgb1-floxed mice with mice expressing thyl-driven YFP, which labels layer $\mathrm{V}$ excitatory neurons, and compared $\operatorname{Itgbl}^{+}$and $\operatorname{Itgb1}^{-}$neurons (Fig. 3A). Manual dendritic spine counting revealed that earlylife knock-down reduced dendritic spine densities $\left(t_{(16)}=2.9\right.$, 

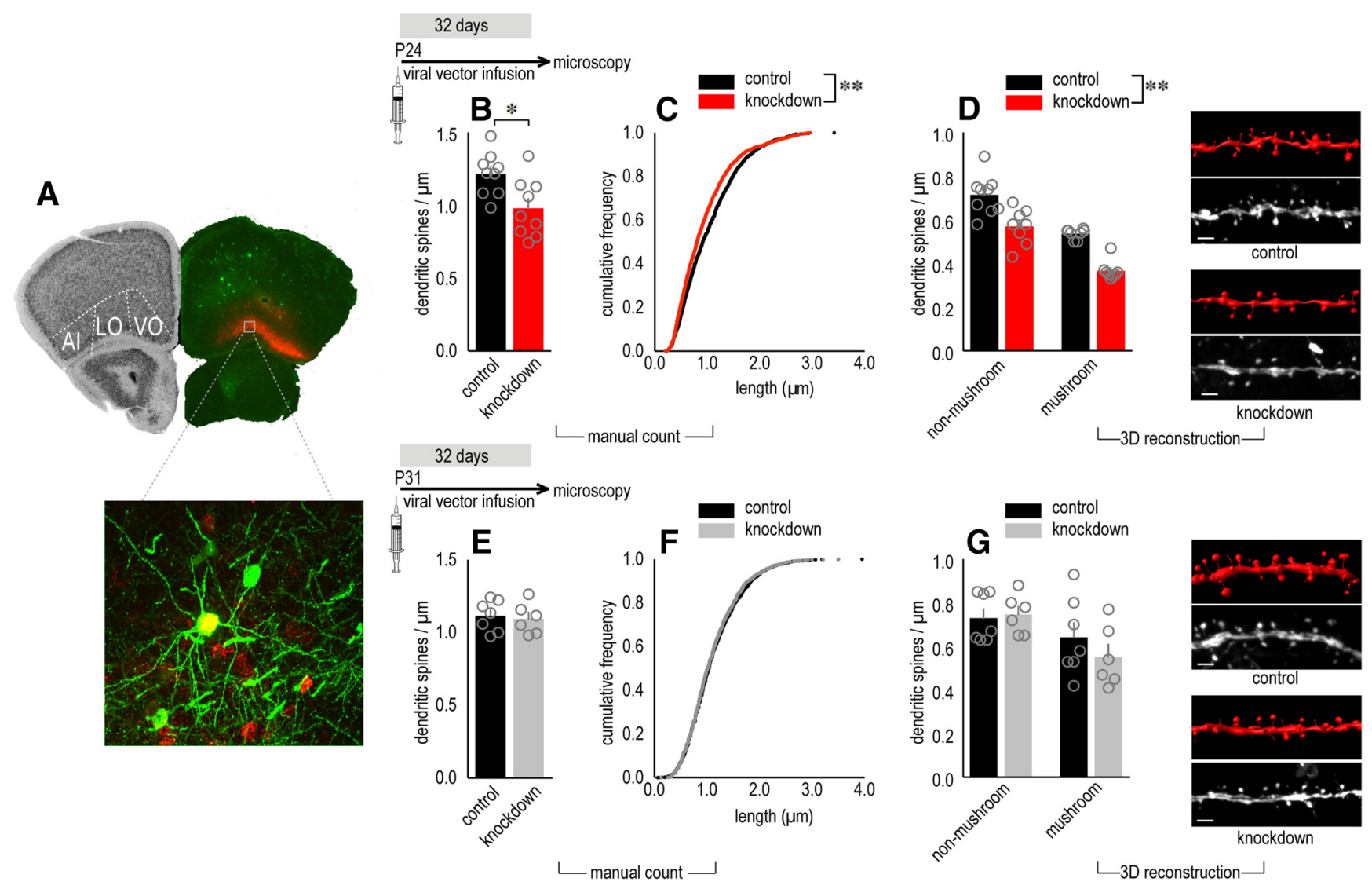

Figure 3. $\beta 1$-integrins in the developing OFC are necessary for dendritic spine stability. Experimental timelines are shown at the top of each row. $A$, Representative $\mathrm{mCherry} \mathrm{expression} \mathrm{in} \mathrm{the} \mathrm{OFC}$ of YFP-expressing floxed Itgb 1 mice. The contralateral hemisphere outlines the subregions of the OFC on a coronal section from the Mouse Brain Library (Rosen et al., 2000). A neuron coexpressing $\mathrm{mCherry}$ and YFP is shown below. $\boldsymbol{B}, \boldsymbol{C}$, Manual spine counting revealed that early-life ltgb 1 knock-down decreased dendritic spine densities $(\boldsymbol{B})$ and dendritic spine length $(\boldsymbol{C})$. D, Dendritic spines were reconstructed in $3 \mathrm{D}$ by a separate rater. Densities were again diminished in the knock-down group regardless of spine subtype (i.e., main effect of knock-down). Representative dendrites, with their associated 3D reconstructions, are adjacent ( $n=9$ control, $n=9$ knock-down hemispheres). $\boldsymbol{E}, \boldsymbol{F}$, In contrast to the effects of early-life knock-down, viral vector infusion at $P 31$ did not affect dendritic spine density $(\boldsymbol{E})$ or length $(\boldsymbol{F})$. $\boldsymbol{G}, 3 \mathrm{D}$ reconstruction revealed that knock-down did not affect the densities of non-mushroom-type or mushroom-type spines $(n=7$ control, $n=6$ knock-down hemispheres). Data are shown as means + SEM, except gray symbols represent individual mice. Individual points in Cand $F$ represent individual spines. ${ }^{*} p<0.05,{ }^{* *} p<0.0001$ versus control. Al, Agranular insular cortex; LO, lateral orbital cortex; V0, ventral orbital cortex. Scale bar, $2 \mu \mathrm{m}$. Dendrites were analyzed by two independent, blinded raters.

$p=0.01$; Fig. $3 B$ ) Not all Itgb1-deficient dendritic spines were eliminated, and those that were spared were shorter (Kolmogorov-Smirnov $p<0.0001$; Fig. $3 C$ ), as also occurs with integrin function-blocking peptides applied to hippocampal neurons (Bourgin et al., 2007).

Next, an independent, blinded rater reconstructed dendritic spines in $3 \mathrm{D}$ to classify their subtype, which is closely linked with spine function. Densities were again lower in the knock-down group, including both mushroom-type spines (those likely to be synapse containing) and non-mushroom-type spines (presumed to be immature) (main effect $F_{(1,29)}=45.4, p<0.0001$; no interaction $F<1$; Fig. 3D). In contrast, Itgb1 knock-down initiated at P31 did not affect overall dendritic spine density $\left(t_{(11)}=0.37, p=\right.$ 0.72 ], dendritic spine length (Kolmogorov-Smirnov $p=0.77$ ], or subtype (no effect of virus $F_{(1,22)}=0.47, p=0.5$; no interaction $F<1$; Fig. $3 E-G$ ). Thus, $\beta 1$-integrins early in adolescence, though not later, appear necessary for dendritic spine stabilization (the process by which dendritic spines escape pruning) in the OFC.

Given dendritic spine loss, we hypothesized that Itgb1 silencing would weaken the ability of OFC neurons to process incoming signals, for example from the intrahemispheric PL, the PL being necessary for action-outcome memory formation (Hart et al., 2014). We tested this hypothesis behaviorally. We reduced
Itgb1 in one hemisphere starting in early life, which would cause dendritic spine loss (above). We then used DREADDs to inducibly inactivate the PL in the contralateral hemisphere during testing in adulthood. This procedure creates a so-called "disconnection," because the PL is silenced in one hemisphere where the OFC is by contrast intact, whereas the other hemisphere contains healthy PL neurons projecting to an Itgb1-deficient OFC (Fig. $4 A$ ). Control mice received infusions in the same hemisphere, sparing the contralateral hemisphere, or they received control, fluorophore-expressing viral vectors in one or both hemispheres (Fig. 4A).

Histological analyses revealed that the DREADD-expressing viral vector was largely contained within the anterior dorsomedial prefrontal cortex and in several mice, extended into the ventrally situated medial OFC (involved in the retrieval of outcome identity memories: Bradfield et al., 2015; Fig. 4B). In five control mice and one ipsilateral mouse, posterior spread was detectable, extending as far back as $\sim$ bregma +1.7 and infecting the infralimbic cortex (data not shown). These mice did not obviously differ from the others and were retained.

We aimed to test outcome expectancies in a way that is compatible with the relatively slow time course of the DREADD ligand CNO (Gomez et al., 2017) and sensitive to subtle effects, if any. We singly housed mice, removed access to water, and then 

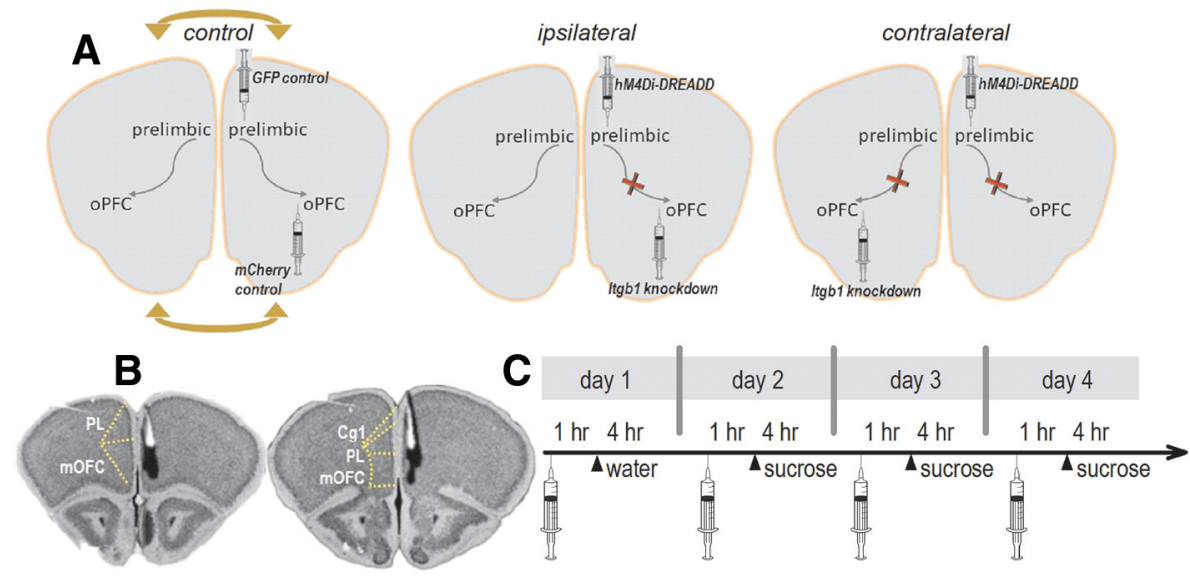

Figure 4. $\quad \beta 1$-integrins in the OFC are necessary for sensitivity to cortical inputs. $\boldsymbol{A}$, Experimental design. Mice were infused unilaterally with control viral vectors or hM4Di-DREADD in the PL and control viral vectors or CaMKII-driven Cre in the $\mathrm{OFC}$, also referred to as the "OPFC". Hemispheres were counterbalanced. When infusions were ipsilateral, one intrahemispheric $\mathrm{PL} \rightarrow 0 \mathrm{FC}$ interaction was unaffected. When infusions were contralateral, both intrahemispheric $\mathrm{PL} \rightarrow 0 \mathrm{FC}$ connections were affected, represented by red crosses. If $\beta 1$-integrins in the OFC sustain sensitivity to intrahemispheric PL inputs, then contralateral infusions will occlude behavioral response updating. The arrows on the control condition indicate that the control group contained ipsilateral and contralateral control viral vectors. $\boldsymbol{B}$, Histological representation of PL infusions, with black representing the largest infusion and white the smallest on coronal sections from the Mouse Brain Library (Rosen et al., 2000). C, Timeline of experimental events, including the administration of the DREADD ligand CN0 to all mice, regardless of viral vector expression, $1 \mathrm{~h}$ before access to water (baseline) or sucrose. $\boldsymbol{D}$, With repeated access to a palatable $1 \% \mathrm{w} / \mathrm{v}$ sucrose solution, intake in control mice increases, presumably as mice develop a sucrose expectation. Intake in mice with contralateral infusions was blunted, suggesting that $\beta 1$-integrins are necessary for OFC sensitivity to intrahemispheric PL inputs that help to develop and sustain expectations. Mice with ipsilateral infusions differed from neither control nor contralateral groups, an apparent intermediate phenotype ( $n=8$ control, $n=9$ ipsilateral, $n=10$ contralateral). Data are shown as mean + SEM. ${ }^{*} p<0.05$ versus control, @p $<0.05$ control mice on the first versus last sucrose day. Cg1, Cingulate cortex, PL= prelimbic cortex, m0FC, medial OFC. This experiment was conducted twice with concordant outcomes; due to baseline consumption differences, one cohort is represented here.

injected them the next day, regardless of viral vector group, with CNO. One hour later, they were allowed access to a sucrose solution for $4 \mathrm{~h}$. We repeated this procedure at the same time of day for 3 consecutive days (Fig. 4C). Typical mice progressively increase their consumption, presumably as they develop a "sucrose expectation." This phenomenon was blocked in the contralateral (disconnection) mice (interaction $F_{(2,24)}=3.82, p=0.04$; Fig. $4 D)$. Thus, $\beta 1$-integrins in the OFC appear necessary for sensitivity to PL inputs that help to develop and sustain outcome expectations. Ipsilateral infusions generated an intermediate phenotype, with the ipsilateral group differing from neither control nor contralateral groups. This pattern is likely attributable to modest dorsomedial prefrontal cortex $\rightarrow$ OFC crossing fibers (Sesack et al., 1989). Groups did not differ in water consumption $(F<1$; Fig. 4D).

\section{Females are resilient to OFC, though not hippocampal, $\boldsymbol{\beta} 1$-integrin loss}

Our experiments described up to this point were conducted using male mice. Next, we bilaterally silenced Itgbl in the OFC in young females, expecting the same outcomes; however, this was not the case. Viral vector infusion at P24 caused no differences in the acquisition of a food-reinforced nose poke response $(F<1$; Fig. $5 A)$ and, unlike in males, sensitivity to action-outcome contingency degradation was intact (main effect of choice $F_{(1,22)}=27.2$, $p<0.001$; no main effect of knock-down or interaction $F<1$; Fig. 5B). Viral vector delivery at P31 also had no effects (response training: $F<1$; probe test: main effect of choice $F_{(1,25)}=11.0$, $p=0.003$, with no effect of knock-down $F_{(1,25)}=1.8, p=0.2$ or interaction $F_{(1,25)}=1.1, p=0.3$; Fig. $\left.5 C, D\right)$. As further confirmation, we delivered viral vectors at P56 and again identified no effects on response training or updating action-outcome expectancies (response training: no main effect of group $F<1$, group $\times$ session interaction $F_{(6,150)}=1.5, p=0.2$; probe test: main effect of choice $F_{(1,25)}=18.35, p<0.001$, with no effect of knock-down or interaction $F<1$; Fig. $5 E, F)$. In the first cohorts of each age group tested, estrous status was collected. It also did not predict response strategies (data not shown).

The lack of effect in females was unexpected, so we silenced Itgbl in the hippocampus (Fig. 5G), where endogenous Itgb1 and $\beta 1$-integrin protein are higher (Grooms et al., 1993; Pinkstaff et al., 1998). $\beta 1$-integrins have been intensively investigated in this region, and our goal was to confirm that Itgb1 deficiency can, under some circumstances, affect females. We trained mice to perform food-reinforced nose poke responses, with no differences in instrumental response training $(F<1$; Fig. $5 H)$. We next extended a lever that had been previously retracted, and mice were reinforced for lever pressing. Such response "reversals" can be sensitive to dorsal hippocampal lesions (Gourley et al., 2010) and, indeed, Itgbl-deficient mice failed to inhibit responding during an extinction phase (main effect of knock-down $F_{(1,19)}=$ 11.7, $p=0.003$; no interaction $F<1$; no effects on acquisition $F<1$; Fig. 5I). Next, mice were administered five unsignaled foot shocks. Freezing increased, with no group differences $(F<1$; Fig. $5 J)$, but when mice were returned to the chambers the following day, Itgb1-deficient mice froze less $\left(t_{(19)}=2.4, p=0.03\right.$; Fig. $\left.5 J\right)$, indicating impaired contextual fear memory, which is hippocampal dependent (Chen et al., 1996). Freezing levels could not be accounted for by estrous status $(F<1$; Fig. $5 K)$. Thus, $\beta 1-$ integrins are necessary for hippocampal-dependent learning and memory in females, as previously reported in males (Babayan et al., 2012; Warren et al., 2012).

\section{Stimulating trkB can compensate for $\beta 1$-integrin loss}

Prior investigations by the Lynch laboratory revealed that the sex hormone estradiol enhances $\beta 1$-integrin-dependent synaptic responses and coactivates the neurotrophin receptor trkB (Wang et al., 2016). This phenomenon could conceivably account for resilience to OFC Itgb1 deficiency in females. Following this logic, we hypothesized that stimulating trkB in males might confer resilience to $\beta 1$-integrin loss. We treated Itgb1-deficient males with 


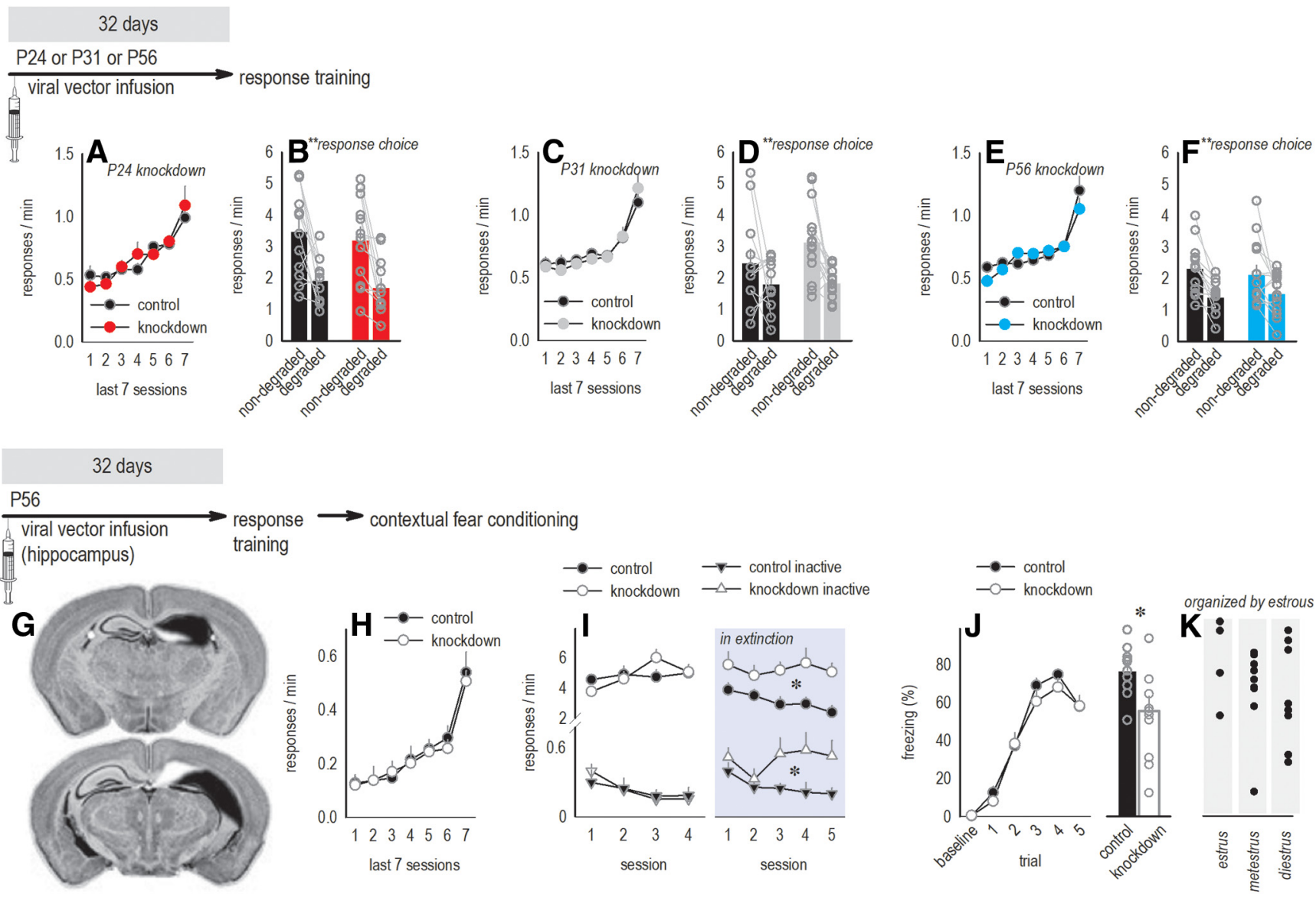

Figure 5. Females are resilient to $\mathrm{OFC}$, though not hippocampal, $\beta 1$-integrin loss. Experimental timelines at the top of each row. $\boldsymbol{A}, \boldsymbol{B}$, Developmental (P24) $0 \mathrm{FC} / \mathrm{tg}$ b $1 \mathrm{knock}$-down in females had no effects on instrumental response training $(\boldsymbol{A})$ nor action- outcome-based responding $(\boldsymbol{B})(n=12 /$ group). $\boldsymbol{C}, \boldsymbol{D}$, Viral vector infusion later, at P31, also had no effects $(n=11$ control, $n=16$ knock-down). $\boldsymbol{E}, \boldsymbol{F}$, Viral vector infusion at P56 had no effects ( $n=13$ control, $n=14 \mathrm{knock}$-down). $G$, As a positive control, we infused Cre into the hippocampus of mature female floxed $/ \mathrm{tg} b 1$ mice. The largest and smallest dorsal hippocampal viral vector spread is represented on the right hemispheres of images from the Mouse Brain Atlas (Rosen et al., 2000$)$ ( $n=10$ control, $n=11$ knock-down). $\boldsymbol{H}$, Mice acquired food-reinforced nose poke responses, with no group differences. $I$, Left, The response requirement was then "reversed" to a previously retracted lever. Mice readily developed the lever press response, inhibiting the previously reinforced nose poke response, referred to as "inactive." Groups did not differ. Right, When reinforcement was withheld entirely, knock-down mice generated perseverative responding, indicating impaired extinction. J, Left, In a contextual fear conditioning procedure, freezing progressively increased in both groups. Right, The following day, context-elicited freezing was lower in knock-down mice, indicating impaired context conditioning. $\boldsymbol{K}$, Freezing was not affected by estrous status, indicated on the $x$-axis. (No mice were determined to be in proestrus.) Data are shown as means + SEM, except gray/black symbols represent individual mice. ${ }^{*} p<0.05$ versus control, ${ }^{* *} p \leq 0.003$ main effect of response choice, with no interactions. Experiments in $\boldsymbol{A}$ to $\boldsymbol{F}$ were conducted at least twice. Experiments in $\boldsymbol{G}$ to $\boldsymbol{K}$ were conducted once, with outcomes concordant with prior investigations (Babayon et al., 2012).

the trkB agonist 7,8-DHF from P31 to P38 (Fig. 6A). Stress hormone exposure during approximately this same period can impair response updating in the same task (Barfield et al., 2017), so we included control mice that did not receive injections. Control groups did not differ (all $p s>0.27$ ) and were combined for statistical analyses. No groups differed in nose poke response training as adults $(F<1 ;$ Fig. $6 B)$. Knock-down mice treated with vehicle were unable to modify response selection strategies when action-outcome contingencies changed, as expected (Fig. $2 D, F)$. 7,8-DHF reinstated response preference (virus $\times 7,8$ DHF interaction $F_{(1,34)}=4.0, p=0.05$; Fig. $\left.6 C\right)$, inducing female-like resilience in males. Thus, stimulating trkB corrected response updating failures due to Itgb1 loss. Age- and sexdependent behavioral effects of developmental Itgb1 silencing are summarized in Table 1.

\section{Discussion}

Ventrolateral OFC lesions and inducible inactivation in mice, rats, and nonhuman primates cause failures in selecting actions based on expected consequences, resulting in a bias toward familiar, habit-like behaviors (Gourley et al., 2013a; Gremel and Costa, 2013; Jackson et al., 2016; Fiuzat et al., 2017; Zimmermann et al., 2017, 2018; Parkes et al., 2018). OFC inactivation also impedes conditioned fear extinction (Zimmermann et al., 2018). Some molecular mechanisms have been identified, but developmental factors are virtually unknown despite protracted postnatal development of the frontal cortex. We argue that developmental $\beta 1$-integrins are indispensable for expectancy updating given that mice lacking $\beta 1$-integrins early in life (viral vectors infused at P24) failed to appropriately modify familiar reward- and fear-related behaviors later in life. Behavioral abnormalities were associated with dendritic spine loss on excitatory neurons in the OFC and insensitivity to cortical inputs. Meanwhile, knock-down initiated in late adolescence spared response updating and neuron structure alike. $\beta 1$-integrins and certain ligands and neuronal substrates are modified by stressors, stress hormones, and drugs of abuse in rodents (Morsink et al., 2006; Wiggins et al., 2009; Hinwood et al., 2013; Lo Iacono et al., 2017; Shapiro et al., 2017b) and humans (Mash et al., 2007). Exposure to excess stress or drugs during specific critical periods may 

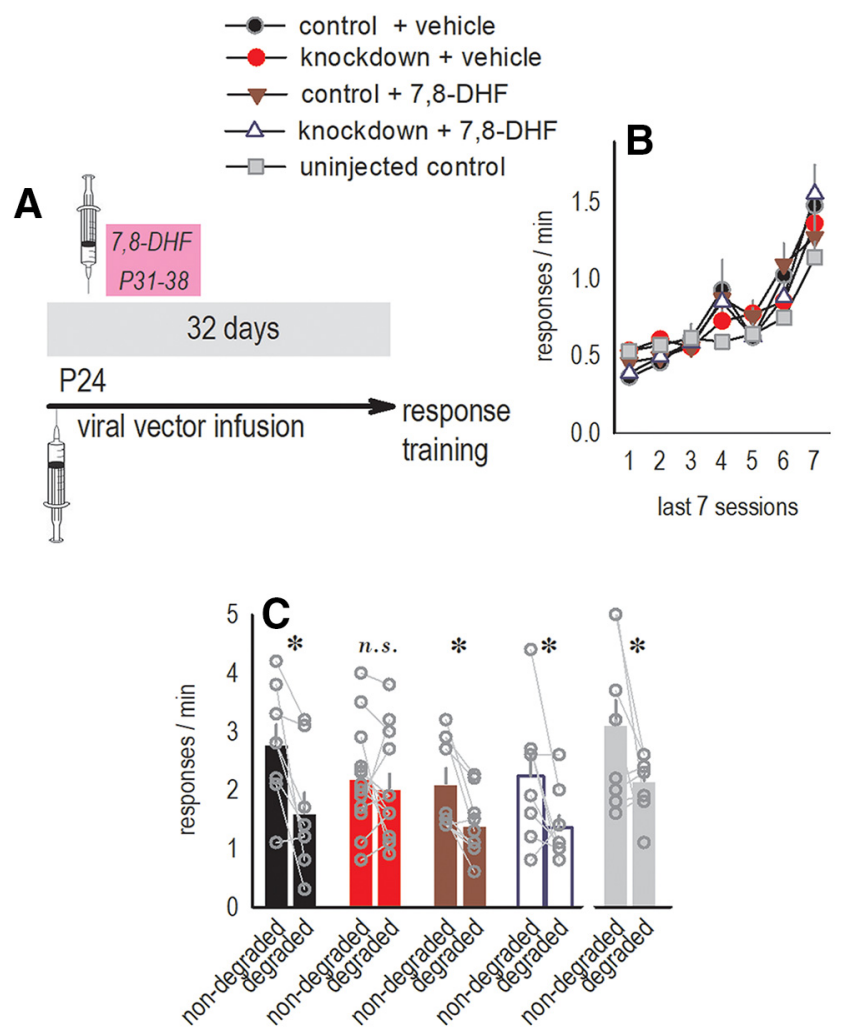

Figure 6. Stimulating trkB during an early-life sensitive period can compensate for the loss of $\beta 1$-integrins in males. $\boldsymbol{A}$, Timeline. Viral vectors were infused and then mice were injected with the trkB agonist 7,8-DHF, vehicle, or nothing at all (uninjected control group) during adolescence. $\boldsymbol{B}$, As adults, mice were trained to respond on two nose poke apertures for food reinforcers. Response rates represent both responses/min. Groups did not differ. $C$, Itgb 1 knockdown impaired the ability of mice to differentiate between responses after action- outcome contingency degradation, as in Figure 2, D and F. 7,8-DHF restored preferential responding. Injection stress during adolescence did not have any apparent consequences (black vs gray bars). $(n=8$ control + vehicle, $n=13$ knock-down + vehicle, $n=9$ control $+7,8$-DHF, $n=$ 8 knock-down $+7,8$-DHF, $n=8$ uninjected controls). Data are shown as means + SEM, except gray symbols represent individual mice. ${ }^{*} p \leq 0.05$. This experiment was conducted four times. n.s., not significant.

Table 1. Age- and sex-dependent effects of developmental $\beta 1$-integrins on expectancy updating

\begin{tabular}{llll}
\hline $\begin{array}{l}\text { Age of viral vector infusion } \\
\text { into the OFC }\end{array}$ & Sex & $\begin{array}{l}\text { Effect on expectancy } \\
\text { updating }\end{array}$ & Figure(s) \\
\hline P24 & M & $\begin{array}{l}\text { Impaired conditioned fear } \\
\text { extinction and reward-related } \\
\text { action-outcome responding }\end{array}$ & $2 A, B, 2 D, 2 F, 6 C$ \\
& \multicolumn{3}{c}{$\begin{array}{l}\text { corrected by a trkB agonist } \\
\text { P31 }\end{array}$} \\
P24 & M & $\emptyset$ & 21 \\
P31 & F & $\emptyset$ & $5 B$ \\
P56 & F & $\emptyset$ & $5 D$ \\
\hline
\end{tabular}

The behavioral effects of OFC-selective viral-mediated Itgb1 silencing at different ages and in both sexes are summarized. $\emptyset$, No change.

thereby have long-term consequences, weakening one's ability to flexibly update expectations later in life.

\section{$\beta 1$-integrins during a critical postnatal period support OFC structure and function}

The majority of our behavioral investigations assessed the ability of mice to select actions based on their consequences. We used a task in which mice first learn to generate two food-reinforced nose pokes equivalently, then one behavior ceases to be reinforced, requiring mice to update expectancies and redirect responding. The PL is necessary for initially acquiring and consolidating information regarding action-outcome relationships (Ostlund and Balleine, 2005; Hart and Balleine, 2016; Swanson et al., 2017; Hart et al., 2018). The OFC is thought to build "task spaces" (Wilson et al., 2014; Stalnaker et al., 2015), essential to updating known associations. Here, mice lacking Itgbl in the OFC failed to modify behaviors when action-outcome contingencies changed. We envision that $\beta 1$-integrin loss degrades the task space, thereby weakening expectations. Supporting this notion, auditory and visual stimuli "bridging" the brief delay between a response and reinforcer eliminated group differences in selecting between reinforced and nonreinforced behaviors. Such cues literally signal reinforcer availability and facilitate response discrimination (Rescorla, 1982), absolving the need for the task space.

Behavioral impairments were attributable to loss of neuronal, rather than glial, Itgb1 (see Paulus et al., 1993; Zhang et al., 2014), given that AAV-CaMKII-driven gene knock-down, affecting excitatory neurons, triggered behavioral abnormalities. And importantly, when viral vector infusion was delayed from P24 until P31, it had no effects. Why might this be? On layer V OFC neurons, dendritic spines proliferate between P24 and P31, followed by a period of pruning during adolescence (Gourley et al., 2012a). AAVs express gradually, with robust expression 1 week after infusion and maximal neuronal expression by $2-3$ weeks (Reimsnider et al., 2007; Taymans et al., 2007; Ahmed et al., 2004). Thus, AAV delivery at P24 would compromise Itgb1 when dendritic spine density is high and vulnerable to elimination. Spines on OFC neurons were indeed lost with early-onset AAVmediated gene knock-down. Thus, $\beta 1$-integrins appear necessary for cortical dendritic spine stabilization during adolescence ("stabilization" referring here to the process by which spines escape age-typical elimination). In cultured hippocampal neurons, anti$\beta 1$-integrin antibodies do not themselves eliminate dendritic spines, but instead, block dendritic spine plasticity in response to LTP-induction trains (Kramár et al., 2006) or metalloproteinases (Michaluk et al., 2011). Cortical dendritic spine stabilization during adolescence is similarly activity dependent, and our findings suggest that $\beta 1$-integrins early on, though not later, are indispensable.

Notably, not all Itgb1-deficient dendritic spines were eliminated and those that were spared were shorter. Spine necks are thought to segregate $\mathrm{Ca}^{2+}$ from the dendritic shaft to support excitatory plasticity, thus reduced spine length could compromise OFC neuron plasticity.

$\beta 1$-integrin-containing dendritic spines presumably receive inputs necessary for OFC function, so we tested whether $\beta 1$-integrins support sensitivity to incoming projections. $\beta 1$ integrin, a postsynaptic component, was silenced unilaterally. To manipulate a presynaptic projection, we delivered inhibitory DREADDs to either the ipsilateral or contralateral PL. In the ipsilateral condition, one intrahemispheric $\mathrm{PL} \rightarrow \mathrm{OFC}$ connection was affected. In the contralateral condition, both intrahemispheric $\mathrm{PL} \rightarrow \mathrm{OFC}$ connections were affected: Intrahemispheric $\mathrm{PL}$ projections terminated on Itgb1-deficient OFC neurons in one hemisphere, while the inactivated PL would be unable to communicate with a healthy OFC in the opposite hemisphere. We anticipated that manipulating these highly specific anatomical connections, and leaving others intact, might generate behavioral effects that would be subtle and best detected using repeating measures. Meanwhile, our instrumental contingency degradation procedure has limited resolution for uncovering 
subtle phenomena. We thus created conditions in which mice updated expectations gradually by giving them routine, daily access to sucrose. Typical mice increase their intake over time, presumably developing a sucrose expectation. Contralateral infusions mitigated intake, suggesting that $\beta 1$-integrins in the OFC sustain sensitivity to PL input, necessary for expectancy updating.

The connections between the PL and ventrolateral OFC (the OFC subregion affected here) are bidirectional (Heidbreder and Groenewegen, 2003; Hoover and Vertes, 2011), but we think the behavioral consequences of contralateral infusions are attributable to $\mathrm{PL} \rightarrow \mathrm{OFC}$ projections, given that $\beta 1$-integrins are located at the postsynaptic synapse (Mortillo et al., 2012). PL $\rightarrow$ OFC projections terminate in all layers and are largely, though not exclusively, intrahemispheric (Sesack et al., 1989; Murphy and Deutch, 2018). Thus, crossing fibers could account for an intermediate effect observed in the ipsilateral PL $\rightarrow \mathrm{OFC}$ condition.

The OFC is largely studied in the context of reward-related decision making, but is also involved in fear-related learning and memory, as noted above (for review, see Shiba et al., 2016). Ventrolateral OFC inactivation impedes the formation and retention of fear extinction memory (Zelinski et al., 2010; Zimmermann et al., 2018), as with Itgb1 knock-down here. We speculate that the healthy ventrolateral OFC interacts with the basolateral amygdala (BLA) to support fear extinction (see Zimmermann et al., 2017 for OFC $\rightarrow$ BLA projections and McDonald, 1987 for $\mathrm{BLA} \rightarrow \mathrm{OFC}$ ). We attempted to test this hypothesis using a "disconnection" design, as above. Itgb1 knock-down in a single OFC hemisphere-regardless of BLA manipulation-was sufficient to impede extinction, however (S.L.G., unpublished data). This outcome occluded our ability to investigate this circuit using asymmetric infusions, but it underscores the importance of OFC $\beta 1$-integrins in extinguishing conditioned fear.

\section{Vulnerability and resilience to Itgb1 loss}

Surprisingly, females were resilient to $\beta 1$-integrin loss. One possible explanation is that females are able to recruit other brain regions to update action-outcome expectancies, a notion supported by early evidence that OFC lesions spare action-outcome conditioning in female rats (Ostlund and Balleine, 2007). Nevertheless, more recent reports indicate that both male and female mice use the OFC to update action-outcome expectancies (Swanson et al., 2015; Baltz et al., 2018). Another consideration is that estradiol activates neuronal $\beta 1$-integrins to facilitate synaptic transmission (Wang et al., 2016). Our viral vector strategy reduced, but did not eliminate, $\beta 1$-integrins, leaving open the possibility that higher estradiol levels in females stimulated remaining $\beta 1$-integrins to overcome the behavioral consequences of gene silencing.

In addition to $\beta 1$-integrins, estradiol transactivates trkB (Wang et al., 2016), which is notable because trkB-mediated signaling is necessary for OFC-dependent response updating (Pitts et al., 2018). We thus attempted to confer resilience to Itgb1 deficiency by stimulating trkB. We treated males with the trkB agonist 7,8-DHF using a systemic dose that phosphorylates trkB and signaling partners in the brain (Barfield et al., 2017). We selected a 1-week period from P31-P38 because it corresponds with when AAV expression would be high in our P24 infusion group, but moderate in our unaffected P31 group (Ahmed et al., 2004). Also during this time, estradiol levels increase in females (Bell, 2018) and levels and activity of a key $\beta 1$-integrin signaling partner, p190RhoGAP, as well as trkB, increase (Shapiro et al., 2017a,b). These changes could confer resilience to $\beta 1$-integrin loss in young females and late-onset knock-down males alike. 7,8-DHF corrected decision making abnormalities in early-life knock-down males, as hypothesized. Understanding direct trkB- $\beta 1$-integrin interactions (if any) on OFC pyramidal neurons will be an important next step in future experiments.

\section{Conclusions}

Implications of our findings are that early-life $\beta 1$-integrins are essential to OFC function, potentially affecting complex decision making across the lifespan, and $\beta 1$-integrins in the more mature OFC are of marginal importance. This latter conclusion is surprising, given that $\beta 1$-integrins are involved in LTP in mature hippocampal slices (Wang et al., 2016), and adult-onset Itgb1 knock-down in the hippocampus interferes with hippocampal function (Fig. 5). Also, inhibiting a primary $\beta 1$-integrin substrate, Abl2/Arg kinase, in the adult OFC impairs reward-related response updating (DePoy et al., 2017). A possible explanation is that mature OFC neurons are better able to upregulate compensatory adhesion factors such as $\mathrm{N}$-cadherin and neuroligins in the absence of $\beta 1$-integrins (Mortillo et al., 2012). Another possible line of future investigation pertains to evidence that variants in the $\beta 1$-integrin-related gene ITGBL1 in humans are associated with cocaine abuse (Drgon et al., 2010), which weakens OFCdependent decision making across rodent and primate species (for review, see DePoy and Gourley, 2015). Stimulating neuronal $\beta 1$-integrin-mediated signaling could potentially combat cocaineinduced degradation of OFC-dependent decision making, particularly in cases of exposure in adolescence, a time of life when rates of drug experimentation are high. This hypothesis could be tested using malleable rodent models.

\section{References}

Ahmed BY, Chakravarthy S, Eggers R, Hermens WT, Zhang JY, Niclou SP, Levelt C, Sablitzky F, Anderson PN, Lieberman AR, Verhaagen J (2004) Efficient delivery of cre-recombinase to neurons in vivo and stable transduction of neurons using adeno-associated and lentiviral vectors. BMC Neurosci 5:4.

Babayan AH, Kramár EA, Barrett RM, Jafari M, Häettig J, Chen LY, Rex CS, Lauterborn JC, Wood MA, Gall CM, Lynch G (2012) Integrin dynamics produce a delayed stage of long-term potentiation and memory consolidation. J Neurosci 32:12854-12861.

Baltz ET, Yalcinbas EA, Renteria R, Gremel CM (2018) Orbital frontal cortex updates state-induced value change for decision making. Elife 7:e35988.

Barfield ET, Gerber KJ, Zimmermann KS, Ressler KJ, Parsons RG, Gourley SL (2017) Regulation of actions and habits by ventral hippocampal trkB and adolescent corticosteroid exposure. PLoS Biol 15:e2003000.

Barker JM, Torregrossa MM, Taylor JR (2013) Bidirectional modulation of infralimbic dopamine D1 and D2 receptor activity regulates flexible reward seeking. Front Neurosci 7:126.

Bell MR (2018) Comparing postnatal development of gonadal hormones and associated social behaviors in rats, mice, and humans. Endocrinology 159:2596-2613.

Bourgin C, Murai KK, Richter M, Pasquale EB (2007) The EphA4 receptor regulates dendritic spine remodeling by affecting $\beta 1$-integrin signaling pathways. J Cell Biol 178:1295-1307.

Bradfield LA, Dezfouli A, van Holstein M, Chieng B, Balleine BW (2015) Medial orbitofrontal cortex mediates outcome retrieval in partially observable task situations. Neuron 88:1268-1280.

Butkovich LM, DePoy LM, Allen AG, Shapiro LP, Swanson AM, Gourley SL (2015) Adolescent-onset $\mathrm{GABA}_{\mathrm{A} \alpha 1}$ silencing regulates reward-related decision making. Eur J Neurosci 42:2114-2121.

Byers SL, Wiles MV, Dunn SL, Taft RA (2012) Mouse estrous cycle identification tool and images PLoS One 7:e35538.

Chan CS, Weeber EJ, Zong L, Fuchs E, Sweatt JD, Davis RL (2006) Beta 1-integrins are required for hippocampal AMPA receptor-dependent synaptic transmission, synaptic plasticity, and working memory. J Neurosci 26:223-232.

Chen C, Kim JJ, Thompson RF, Tonegawa S (1996) Hippocampal lesions 
impair contextual fear conditioning in two strains of mice. Behav Neurosci 110:1177-1180.

Cooper MA, Koleske AJ (2014) Ablation of ErbB4 from excitatory neurons leads to reduced dendritic spine density in mouse prefrontal cortex. J Comp Neurol 522:3351-3362.

DePoy LM, Gourley SL (2015) Synaptic cytoskeletal plasticity in the prefrontal cortex following psychostimulant exposure. Traffic 16:919-940.

DePoy LM, Noble B, Allen AG, Gourley SL (2013) Developmentally divergent effects of rho-kinase inhibition of cocaine- and BDNF-induced behavioral plasticity. Behav Brain Res 243:171-175.

DePoy LM, Zimmermann KS, Marvar PJ, Gourley SL (2017) Induction and blockade of adolescent cocaine-induced habits. Biol Psychiatry 81:595-605.

Drgon T, Zhang PW, Johnson C, Walther D, Hess J, Nino M, Uhl GR (2010) Genome wide association for addiction: replicated results and comparisons of two analytic approaches. PLoS One 5:e8832.

Ehrengruber MU, Hennou S, Büeler H, Naim HY, Déglon N, Lundstrom K (2001) Gene transfer into neurons from hippocampal slices: comparison of recombinant semliki forest virus, adenovirus, adeno-associated virus, lentivirus, and measles virus. Mol Cell Neurosci 17:855-871.

Feng G, Mellor RH, Bernstein M, Keller-Peck C, Nguyen QT, Wallace M, Nerbonne JM, Lichtman JW, Sanes JR (2000) Imaging neuronal subsets in transgenic mice expressing multiple spectral variants of GFP. Neuron 28:41-51.

Fiuzat EC, Rhodes SE, Murray EA (2017) The role of orbitofrontalamygdala interactions in updating action-outcome valuations in macaques. J Neurosci 37:2463-2470.

Gomez JL, Bonaventura J, Lesniak W, Mathews WB, Sysa-Shah P, Rodriguez LA, Ellis RJ, Richie CT, Harvey BK, Dannals RF, Pomper MG, Bonci A, Michaelides M (2017) Chemogenetics revealed: DREADD occupancy and activation via converted clozapine. Science 357:503-507.

Gourley SL, Koleske AJ, Taylor JR (2009) Loss of dendrite stabilization by the abl-related gene (Arg) kinase regulates behavioral flexibility and sensitivity to cocaine. Proc Natl Acad Sci U S A 106:16859-16864.

Gourley SL, Lee AS, Howell JL, Pittenger C, Taylor JR (2010) Dissociable regulation of instrumental action within mouse prefrontal cortex. Eur J Neurosci 32:1726-1734.

Gourley SL, Olevska A, Warren MS, Taylor JR, Koleske AJ (2012a) Arg kinase regulates prefrontal dendritic spine refinement and cocaine-induced plasticity. J Neurosci 32:2314-2323.

Gourley SL, Swanson AM, Jacobs AM, Howell JL, Mo M, Dileone RJ, Koleske AJ, Taylor JR (2012b) Action control is mediated by prefrontal BDNF and glucocorticoids. Proc Natl Acad Sci U S A 109:20714-20719.

Gourley SL, Olevska A, Zimmermann KS, Ressler KJ, Dileone RJ, Taylor JR (2013a) The orbitofrontal cortex regulates outcome-based decision making via the lateral striatum. Eur J Neurosci 38:2382-2388.

Gourley SL, Swanson AM, Koleske AJ (2013b) Corticosteroid-induced neural remodeling predicts behavioral vulnerability and resilience. J Neurosci 33:3107-3112.

Gremel CM, Costa RM (2013) Orbitofrontal and striatal circuits dynamically encode the shift between goal-directed and habitual actions. Nat Commun 4:2264.

Grooms SY, Terracio L, Jones LS (1993) Anatomical localization of $\beta 1$ integrin-like immunoreactivity in rat brain. Exp Neurol 122:253-259.

Hart G, Balleine BW (2016) Consolidation of goal-directed action depends on MAPK/ERK signaling in rodent prelimbic cortex. J Neurosci 36: 11974-11986.

Hart G, Leung BK, Balleine BW (2014) Dorsal and ventral streams: the distinct role of striatal subregions on the acquisition and performance of goal-directed actions. Neurobiol Learn Mem 108:104-118.

Hart G, Bradfield LA, Fok SY, Chieng B, Balleine BW (2018) The bilateral prefronto-striatal pathways is necessary for learning new goal-directed actions. Curr Biol 28:2218-2229.e7.

Heidbreder CA, Groenewegen HJ (2003) The medial prefrontal cortex in the rat: evidence for a dorso-ventral distinction based upon functional and anatomical characteristics. Neurosci Biobehav Rev 27:555-579.

Hinwood M, Tynan RJ, Charnley JL, Beynon SB, Day TA, Walker FR (2013) Chronic stress induced remodeling of the prefrontal cortex: structural re-organization of microglia and the inhibitor effect of minocycline. Cereb Cortex 23:1784-1797.

Hoover WB, Vertes RP (2011) Projections of the medial orbital and ventral orbital cortex in the rat. J Comp Neurol 519:3766-3801.
Huang Z, Shimazu K, Woo NH, Zang K, Müller U, Lu B, Reichardt LF (2006) Distinct roles of the beta 1-class integrins at the developing and the mature hippocampal excitatory synapse. J Neurosci 26:11208-11219.

Jackson SA, Horst NK, Pears A, Robbins TW, Roberts AC (2016) Role of the perigenual anterior cingulate and orbitofrontal cortex in contingency learning in the marmoset. Cereb Cortex 26:3273-3284.

Kerrisk ME, Koleske AJ (2013) Arg kinase signaling in dendrite and synapse stabilization pathways: memory, cocaine sensitivity, and stress. Int J Biochem Cell Biol 45:2496-2500.

Koss WA, Frick KM (2017) Sex differences in hippocampal function. J Neurosci Res 95:539-562.

Kramár EA, Lin B, Rex CS, Gall CM, Lynch G (2006) Integrin-driven actin polymerization consolidates long-term potentiation. Proc Natl Acad Sci U S A 103:5579-5584.

Lo Iacono L, Valzania A, Visco-Comandini F, Aricò E, Viscomi MT, Castiello L, Oddi D, D'Amato FR, Bisicchia E, Ermakova O, Puglisi-Allegra S, Carola V (2017) Social threat exposure in juvenile mice promotes cocaine-seeking by altering blood clotting and brain vasculature. Addict Biol 22:911-922.

Mash DC, ffrench-Mullen J, Adi N, Qin Y, Buck A, Pablo J (2007) Gene expression in human hippocampus from cocaine abusers identifies genes which regulate extracellular matrix remodeling. PLoS One 2:e1187.

McDonald AJ (1987) Organization of amygdaloid projections to the mediodorsal thalamus and prefrontal cortex: a fluorescence retrograde transport study in the rat. J Comp Neurol 262:46-58.

Michaluk P, Wawrzyniak M, Alot P, Szczot M, Wyrembek P, Mercik K, Medvedev N, Wilczek E, De Roo M, Zuschratter W, Muller D, Wilczynski GM, Mozrzymas JW, Stewart MG, Kaczmarek L, Wlodarczyk J (2011) Influence of matrix metalloproteinase MMP-9 on dendritic spine morphology. J Cell Sci 124:3369-3380.

Morsink MC, Steenbergen PJ, Vos JB, Karst H, Joëls M, De Kloet ER, Datson NA (2006) Acute activation of hippocampal glucocorticoid receptors results in different waves of gene expression throughout time. J Neuroendocrinol 18:239-252.

Mortillo S, Elste A, Ge Y, Patil SB, Hsiao K, Huntley GW, Davis RL, Benson DL (2012) Compensatory redistribution of neuroligins and N-cadherin following deletion of synaptic $\beta 1$-integrin. J Comp Neurol 520:20412052.

Murphy MJM, Deutch AY (2018) Organization of afferents to the orbitofrontal cortex in the rat. J Comp Neurol 526:1498-1526.

Ostlund SB, Balleine BW (2005) Lesions of the medial prefrontal cortex disrupt the acquisition but not the expression of goal-directed learning. J Neurosci 25:7763-7770.

Ostlund SB, Balleine BW (2007) Orbitofrontal cortex mediates outcome encoding in Pavlovian but not instrumental conditioning. J Neurosci 27:4819-4825.

Park YK, Goda Y (2016) Integrins in synapse regulation. Nat Rev Neurosci 17:745-756.

Parkes SL, Ravassard PM, Cerpa JC, Wolff M, Ferreira G, Coutureau E (2018) Insular and ventrolateral orbitofrontal cortices differentially contribute to goal-directed behavior in rodents. Cereb Cortex 28:2313-2325.

Paulus W, Baur I, Schuppan D, Roggendorf W (1993) Characterization of integrin receptors in normal and neoplastic human brain. Am J Pathol 143:154-163.

Pinkstaff JK, Lynch G, Gall CM (1998) Localization and seizure-regulation of integrin beta 1 mRNA in adult rat brain. Brain Res Mol Brain Res 55:265-276.

Pitts EG, Li DC, Gourley SL (2018) Bidirectional coordination of actions and habits by TrkB in mice. Sci Rep 8:4495.

Raghavan S, Bauer C, Mundschau G, Li Q, Fuchs E (2000) Conditional ablation of betal integrin in skin. severe defects in epidermal proliferation, basement membrane formation, and hair follicle invagination. J Cell Biol 150:1149-1160.

Reimsnider S, Manfredsson FP, Muzyczka N, Mandel RJ (2007) Time course of transgene expression after intrastriatal pseudotyped rAAV2/1, rAAV2/2, rAAV2/5, rAAV2/8 transduction in the rat. Mol Ther 15:15041511.

Rescorla RA (1982) Effect of a stimulus intervening between CS and US in autoshaping. J Exp Psychol Anim Behav Process 8:131-141.

Rosen GD, Williams AG, Capra JA, Connolly MT, Cruz B, Lu L, Airey DC, Kulkarni K, Williams RW (2000) The mouse brain library. International Mouse Genome Conference, Vol 14, p 166. Available at http://www.mbl.org. 
Rudebeck PH, Behrens TE, Kennerley SW, Baxter MG, Buckley MJ, Walton ME, Rushworth MF (2008) Frontal cortex subregions play distinct roles in choices between actions and stimuli. J Neurosci 28:13775-13785.

Schilman EA, Uylings HB, Galis-de Graaf Y, Joel D, Groenewegen HJ (2008) The orbital cortex in rats topographically projects to central parts of the caudate-putamen complex. Neurosci Lett 432:40-45.

Schuster T, Krug M, Stalder M, Hackel N, Gerardy-Schahn R, Schachner M (2001) Immunoelectron microscopic localization of the neural recognition molecules L1, NCAM, and its isoform NCAM180, the NCAMassociated polysialic acid, betal integrin and the extracellular matrix molecule tenascin- $\mathrm{R}$ in synapses of the adult rat hippocampus. J Neurobiol 49:142-158.

Sesack SR, Deutch AY, Roth RH, Bunney BS (1989) Topographical organization of the efferent projections of the medial prefrontal cortex in the rat: an anterograde tract-tracing study with Phaseolus vulgaris leucoagglutinin. J Comp Neurol 290:213-242.

Shapiro LP, Parsons RG, Koleske AJ, Gourley SL (2017a) Differential expression of cytoskeletal regulatory factors in the adolescent prefrontal cortex: implications for cortical development. J Neurosci Res 95: $1123-1143$.

Shapiro LP, Omar MH, Koleske AJ, Gourley SL (2017b) Corticosteroidinduced dendrite loss and behavioral deficiencies can be blocked by activation of Abl2/Arg kinase. Mol Cell Neurosci 85:226-234.

Shiba Y, Santangelo AM, Roberts AC (2016) Beyond the medial regions of prefrontal cortex in the regulation of fear and anxiety. Front Syst Neurosci 10:12.

Spear LP (2000) The adolescent brain and age-related behavioral manifestations. Neurosci Biobehav Rev 24:417-463.

Spence KW (1947) The role of secondary reinforcement in delayed reward learning. Psychol Rev 54:1-8.

Stalnaker TA, Cooch NK, Schoenbaum G (2015) What the orbitofrontal cortex does not do. Nat Neurosci 18:620-627.

Sul JH, Kim H, Huh N, Lee D, Jung MW (2010) Distinct roles of rodent orbitofrontal and medial prefrontal cortex in decision making. Neuron 66:449-460.

Swanson AM, Allen AG, Shapiro LP, Gourley SL (2015) $\mathrm{GABA}_{\mathrm{A} \alpha 1^{-}}$ mediated plasticity in the orbitofrontal cortex regulates contextdependent action selection. Neuropsychopharmacology 40:1027-1036.

Swanson AM, DePoy LM, Gourley SL (2017) Inhibiting rho kinase promotes goal-directed decision making and blocks habitual responding for cocaine. Nat Commun 8:1861.
Taymans JM, Vandenberghe LH, Haute CV, Thiry I, Deroose CM, Mortelmans L, Wilson JM, Debyser Z, Baekelandt V (2007) Comparative analysis of adeno-associated viral vector serotypes $1,2,5,7$, and 8 in mouse brain. Hum Gene Ther 18:195-206.

Urban DJ, Roth BL (2015) DREADDs (Designer receptors exclusively activated by designer drugs): chemogenetic tools with therapeutic utility. Annu Rev Pharmacol Toxicol 55:399-417.

Van Eden CG, Uylings HB (1985) Postnatal volumetric development of the prefrontal cortex in the rat. J Comp Neurol 241:268-274.

Wang W, Kantorovich S, Babayan AH, Hou B, Gall CM, Lynch G (2016) Estrogen's effects on excitatory synaptic transmission entail integrin and TrkB transactivation and depend upon $\beta 1$ integrin function. Neuropsychopharmacology 41:2723-2732.

Warren MS, Bradley WD, Gourley SL, Lin YC, Simpson MA, Reichardt LF, Greer CA, Taylor JR, Koleske AJ (2012) Integrin $\beta 1$ signals through arg to regulate postnatal dendritic arborization, synapse density, and behavior. J Neurosci 32:2824-2834.

Whyte AJ, Kietzman HW, Swanson AM, Butkovich LM, Barbee BR, Bassell GJ, Gross C, Gourley SL (2019) Reward-related expectations trigger dendritic spine plasticity in the mouse ventrolateral orbitofrontal cortex. J Neurosci 39:4595-4605.

Wiggins AT, Pacchioni AM, Kalivas PW (2009) Integrin expression is altered after acute and chronic cocaine. Neurosci Lett 450:321-323.

Wilson RC, Takahashi YK, Schoenbaum G, Niv Y (2014) Orbitofrontal cortex as a cognitive map of task space. Neuron 81:267-279.

Zelinski EL, Hong NS, Tyndall AV, Halsall B, McDonald RJ (2010) Prefrontal cortical contributions during discriminative fear conditioning, extinction, and spontaneous recovery in rats. Exp Brain Res 203:285-297.

Zhang Y, Chen K, Sloan SA, Bennett ML, Scholze AR, O'Keeffe S, Phatnani HP, Guarnieri P, Caneda C, Ruderisch N, Deng S, Liddelow SA, Zhang C, Daneman R, Maniatis T, Barres BA, Wu JQ (2014) An RNA-seq transcriptome and splicing database of glia, neurons, and vascular cells of the cerebral cortex. J Neurosci 34:11929-11947.

Zimmermann KS, Yamin JA, Rainnie DG, Ressler KJ, Gourley SL (2017) Connections of the mouse orbitofrontal cortex and regulation of goaldirected action selection by brain-derived neurotrophic factor. Biol Psychiatry $81: 366-377$.

Zimmermann KS, Li CC, Rainnie DG, Ressler KJ, Gourley SL (2018) Memory retention involves the ventrolateral orbitofrontal cortex: comparison with the basolateral amygdala. Neuropsychopharmacology 43:373-383. 